\title{
Pleomorfismo de oocistos de Cystoisospora felis (Wenyon, 1923) Frenkel, 1977 (Apicomplexa: Cystoisosporinae) induzido por differentes fontes de infecção*
}

\author{
Pleomorfism of Cystoisospora felis (Wenyon, 1923) Frenkel, 1977 \\ (Apicomplexa: Cystoisosporinae) oocysts induced \\ by different sources of infection
}

Simoni Machado de Medeiros, ${ }^{* *}$ Zelson Giacomo Loss, ${ }^{* *}$ Walter Flausino, ${ }^{* \star * *}$ Carlos Wilson Gomes Lopes ${ }^{\star * * *}$

\begin{abstract}
Resumo
Com o objetivo de avaliar as diferenças morfométricas dos oocistos esporulados de Cystoisospora felis oriundos de diferentes fontes de infecção: natural em gatos peri-domiciliados, experimental induzida por oocistos esporulados e experimental induzida por hipnozoítas em vísceras de camundongos pré-inoculados por via oral com $10^{6}$ oocistos esporulados de $C$. felis, foram utilizados 40 gatos, sendo 28 oriundos de áreas peridomiciliares do município de Seropédica, estado do Rio de Janeiro, dos quais foram obtidos oocistos de $C$. felis por infecção natural e 12 livres de coccídios, nascidos em laboratório. Estes últimos foram divididos em dois grupos com seis animais cada, que receberam por via oral inóculo contendo $10^{6}$ oocistos esporulados e vísceras de camundongos inoculados previamente com $C$. felis, respectivamente. Os oocistos provenientes das três fontes de infecção foram diferentes entre si quando se consideraram os diâmetros polar e equatorial. No entanto, em relação ao índice morfométrico, não houve variação. Os oocistos provenientes de infecção por vísceras foram pouco homogêneos em relação aos oocistos oriundos de infecção experimental com oocistos esporulados e de infecção natural.
\end{abstract}

Palavras-chave: Cystoisospora felis, gatos, fontes de infecção, pleomorfismo.

\begin{abstract}
The present work aimed at to evaluate morphological differences that can be observed on Cystoisospora felis oocysts from natural, oocyst-borne experimental infection and mice viscera-borne experimental infection. For this reason, forty cats were used in this experiment. Twenty-eight cats were taken in the municipality of Seropédica, State of Rio de Janeiro, which were corresponded to natural infection and twelve coccidia-free kittens which were borne inside laboratory facilities. These coccidiafree cats were divided into two groups with six animals each: the first group was inoculated with $10^{6}$ sporulated oocysts and the second one with mice visceras previously inoculated with $10^{6}$ sporulated oocysts. Oocysts shed by these kittens submitted to three sources of infection were different from each other, when were considered the length and width, although there was not variation on the shape index of them. Oocysts proceeding from kittens fed on mice visceras showed lower homogeneity in comparison to oocysts that came from oocyst-to-oocyst experimental and natural infections.
\end{abstract}

Keywords: Cytoisospora felis, cats, oocysts, pleomorfism, source of infection.

\section{Introdução}

A infecção por Cystoisospora felis e C. rivolta em felinos pode ser determinada a partir da observação de oocistos nas fezes, feita por Wenyon (1923), quando descreveu a espécie C. felis como Isospora felis, como também fez Hitchcock (1955), Lickfeld (1959) e Dubey (1979).

Além da elucidação do ciclo biológico, foram identificadas duas possíveis formas da infecção pelas espécies de $C$. felis e C. rivolta em felinos, que podem adquiri-las pela ingestão de oocistos esporulados ou pela ingestão de um hospedeiro intermediário infectado previamente com oocistos esporulados (Shah, 1971; Frenkel e Dubey, 1972).

Vários animais têm sido caracterizados como hospedeiros intermediários de espécies do gênero Cystoisospora, tais como: camundongos, ratos, hamsters (Frenkel e Dubey, 1971), cães (Dubey, 1975), pássaros (Lindsay e Blagburn, 1994)

* Sob os auspícios do CNPq

** Curso de Biologia, Associação Brasileira de Ensino Universitário, Rua Itaiara, 301 Belford Roxo, RJ

*** Departamento de Clínica e Cirurgia Veterinária, Instituto de Veterinária (IV), Universidade Federal Rural do Rio de Janeiro (UFRRJ). BR-465 Km7, CEP 23890-000 Seropédica, RJ. E-mail: zelson@ufrrj.br

**** Departamento de Parasitologia Animal, IV, UFRRJ. BR-465 Km-7. CEP 23890-000 Seropédica, RJ. E-mail: flausino@ufrrj.br e autor para correspondência: e-mail: lopescwg@ufrrj.br 
bovinos (Fayer e Frenkel, 1979, cobaios (Herzog et al., 1993), coelhos (Costa e Lopes, 1998), suínos (Melo et al., 2003; Carvalho Filho et al., 2003), frangos (Massad et al., 2003) e gerbils da Mongólia (Oliveira et al., 2007) onde são observados em seus órgãos viscerais cistos monozóicos.

Estudando a freqüência de hipnozoítas de $C$. felis em vísceras de camundongos albinos infectados experimentalmente com oocistos esporulados desta espécie, Freire e Lopes (1996) observaram afinidade biológica destas formas pelo fígado, baço, linfonodos mesentéricos e placas de Payer. Resultado semelhante foi observado por Costa e Lopes (1998) em coelhos tipo carne infectados com oocistos esporulados do mesmo parasito.

Recentemente foi observado, através de uma estimativa de eliminação de oocistos, que a infecção de gatos com vísceras de suínos pré-inoculados com $10^{6}$ oocistos esporulados de C. felis pode induzir a eliminação de pelo menos 15 vezes mais oocistos nas fezes do que a infecção do mesmo hospedeiro definitivo com inóculo similar ao dado aos suínos infectados experimentalmente (Carvalho Filho et al., 2003). Além disso, Frenkel e Dubey (1972) já afirmavam que a presença e a quantidade de parasitos por órgãos de um animal infectado irão depender da dose infectante.

Este trabalho teve como objetivo determinar o pleomorfismo dos oocistos esporulados de $C$. felis induzidos por diferentes fontes de infecção.

\section{Material e métodos}

Foi utilizado um total de 40 gatos (Felis catus) de ambos os sexos, procedentes do município de Seropédica, RJ, sendo 28 de diferentes idades, mantidos em gaiolas individuais e alimentados com peixe cru infectados naturalmente, sendo considerados como doadores de oocistos de C. felis. Os 12 animais restantes, nascidos em laboratório eram negativos para coccídios.

As fezes, eliminadas por 28 animais que serviram como doadores de $C$. felis, foram examinadas por 30 dias para determinar a presença de oocistos, utilizando-se a técnica de cintrífugo-flutuação conforme Menezes e Lopes (1995). Parte das fezes positivas para $C$. felis foram diluídas em dicromato de potássio a 2,5\% (1:3) e colocadas em placas de Petri para esporularem a temperatura ambiente.

Para a infecção experimental com vísceras foram utilizadas seis fêmeas de camundongos albinos (Mus muculus) Swiss com peso aproximado de $20 \pm 2 \mathrm{~g}$. A seguir foram infectados por via oral com $10^{6}$ oocistos esporulados de $C$. felis oriundos dos felinos doadores de oocistos.

Os 12 animais nascidos em laboratório, todos negativos para coccídios conforme técnica preconizada por Loss e Lopes (1997). A seguir estes gatinhos foram divididos em dois grupos de seis animais. Ao primeiro grupo foi administrado por via oral $10^{6}$ oocistos esporulados de C. felis obtidos da infecção natural (infecção experimental 1). Os animais do segundo grupo foram alimentados com vísceras de camundongos previamente infectados por via oral com $10^{6}$ oocistos esporulados, estando estes animais no 30 dia após infecção (infecção experimental 2).

Para análise e caracterização morfológica de 100 oocistos esporulados procedentes de cada uma das fontes de infecção utilizou-se uma ocular micrométrica K-15X PZO em um microscópio binocular Carl Zeiss. As fotografias foram obtidas com auxílio de um microscópio triocular modelo jenapol da Zeiss-Jena com filme Kodak de 100 ISO.

As medidas de tendência central, bem como as comparações entre os oocistos das diferentes fontes de infecção foram analisadas com base em Sampaio 2002.

\section{Resultados e discussão}

Para análise e caracterização dos oocistos (Figura 1) são necessários conhecer os aspectos taxionômicos que, nesses protozoários, se apoiado nas características morfológicas dos oocistos (Tenter et al., 2002) e biológicas, algumas vezes estas podem ser utilizadas como meio de diagnóstico de rotina na identificação da espécie estudada.

Ao se comparar os oocistos de C. felis, procedentes das infecções pré-estabelecidas (Tabela 1), observou-se que ocorreram variações intra-específicas que modificaram a morfometria dos oocistos esporulados. Considerações semelhantes foram feitas para espécies do gênero Eimeria parasitas de aves (Norton e Joyner, 1981), para Hammondia heydroni (Pereira et al., 2002), em E. opimi de tuco-tuco (Ctenomys boliviensis) por Gardner e Duszinski (1990) e para Cryptosporidium muris (Bomfim e Lopes, 1998). Essas variações intra-específicas puderam ser evidenciadas quando foram comparadas as análises gráficas dos oocistos de $C$. felis em diferentes tipos de infecção.

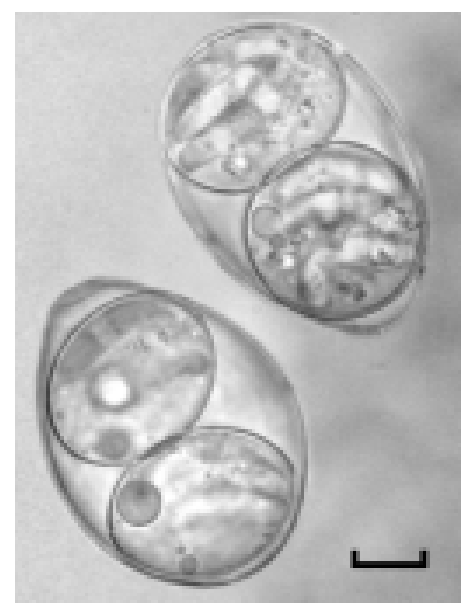

Figura 1: Oocistos esporulados de Cystoisospora felis. Solução saturada de açúcar. (Barra= 10 $\mu \mathrm{m})$

Tabela 1: Dimensões dos oocistos de Cystoisospora felis presentes em amostras fecais obtidas de felinos, submetidos a diferentes fontes de infecção

\begin{tabular}{l|c|c|c}
\hline \multirow{2}{*}{$\begin{array}{c}\text { Tipo de } \\
\text { infecção }\end{array}$} & \multicolumn{2}{|c|}{ Diâmetros $(\mathrm{mm})^{1}$} & \multirow{2}{*}{ Índice morfométrico } \\
\cline { 2 - 3 } & Maior & Menor & \\
\hline Camundongos $^{2}$ & $41,55 \pm 2,19^{\mathrm{a}}$ & $33,13 \pm 1,75^{\mathrm{a}}$ & $1,26 \pm 0,08(100)^{4}$ \\
\hline Oocistos $^{3}$ & $40,55 \pm 2,06^{\mathrm{b}}$ & $32,20 \pm 1,75^{\mathrm{b}}$ & $1,26 \pm 0,09(100)$ \\
\hline Natural & $33,43 \pm 1,58^{\mathrm{c}}$ & $26,72 \pm 1,30^{\mathrm{c}}$ & $1,25 \pm 0,06(100)$ \\
\hline
\end{tabular}

${ }^{1}$ Letras diferentes por coluna significantes pelo test 1 de Tukey com $p<0,001$. 'Infecção experimental com vísceras de camundongos.

${ }^{3}$ Infecção experimental com oocistos esporulados.

${ }^{4}$ Valores entre parênteses equivalem a número de oocistos medidos. 
Na Figura 2, quando foram analisados os intervalos de classe, verificou-se uma variação nos oocistos oriundos de infecção natural em gatos adultos, onde se observou maior eliminação de oocistos no intervalo de 38,80 e 40,20 mm para diâmetro polar e no de 30,95 a $32,10 \mathrm{~mm}$ para diâmetro equatorial. $\mathrm{Na}$ infecção experimental I (Figura 3), onde gatos jovens receberam oocistos esporulados de C. felis, houve uma distribuição homogênea nos intervalos de classe para diâmetros polar e equatorial, onde as medidas foram semelhantes à infecção natural dos adultos. Já, na infecção experimental II (Figura 4), onde os gatos jovens receberam vísceras de camundongos com hipnozoítas de $C$. felis, foi verificado que a distribuição das medidas dos oocistos foi pouco homogênea, muito semelhante ao observado com os oocistos dos animais adultos por infecção natural. O aumento do número de oocistos eliminados pode estar relacionado ao confinamento dos animais, porém, outros fatores podem estar relacionados com diferenças genéticas das raças, cepas dos parasitos, a fatores estressantes ou mesmo com o uso de drogas que tenham efeito sobre coccídios (Fayer, 1980).
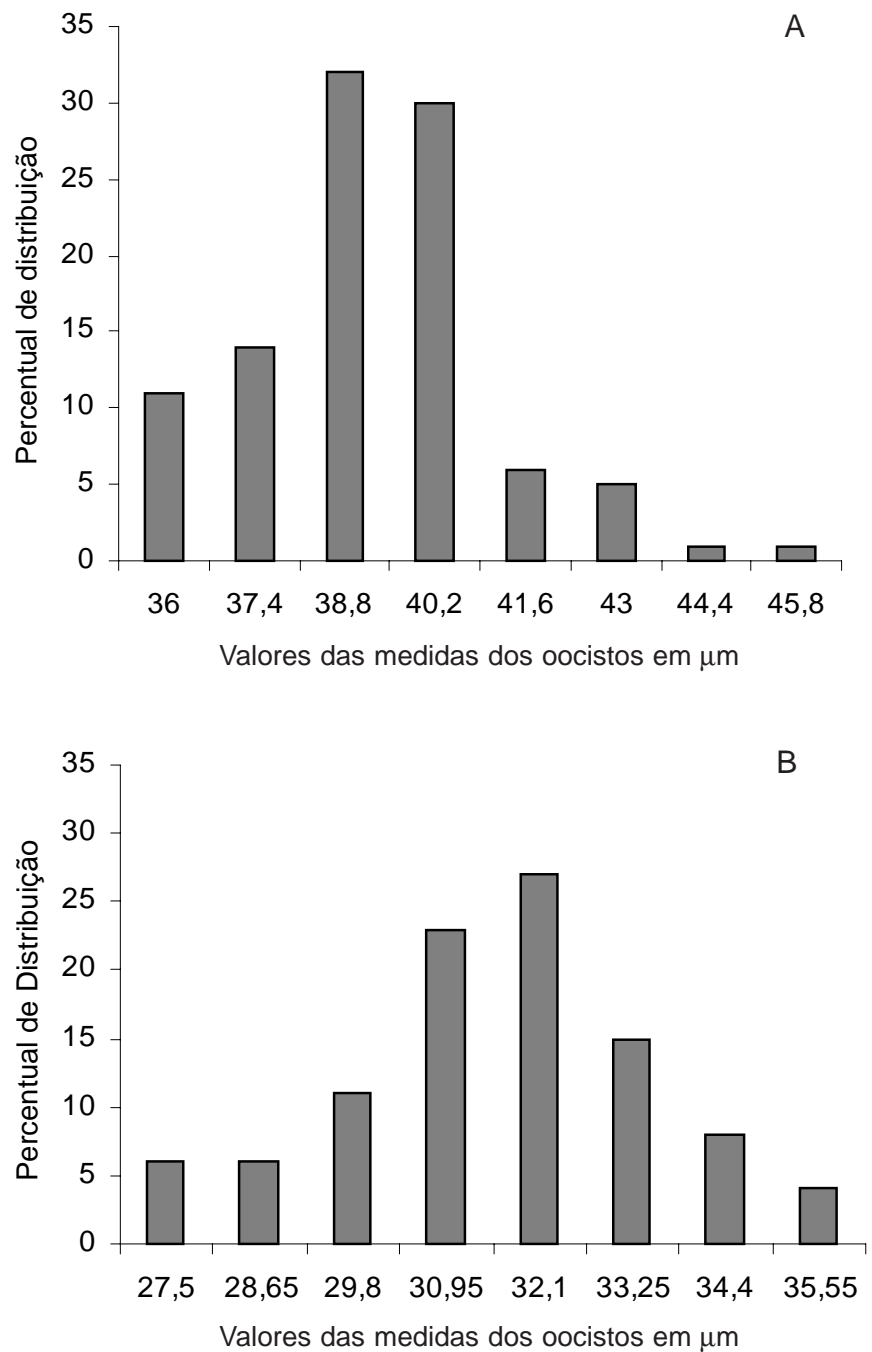

Figura 2: Intervalo de classe de oocistos esporulados de Cystoisospora felis oriundos de infecção natural de gatos. Diâmetros, maior (A) e menor (B).
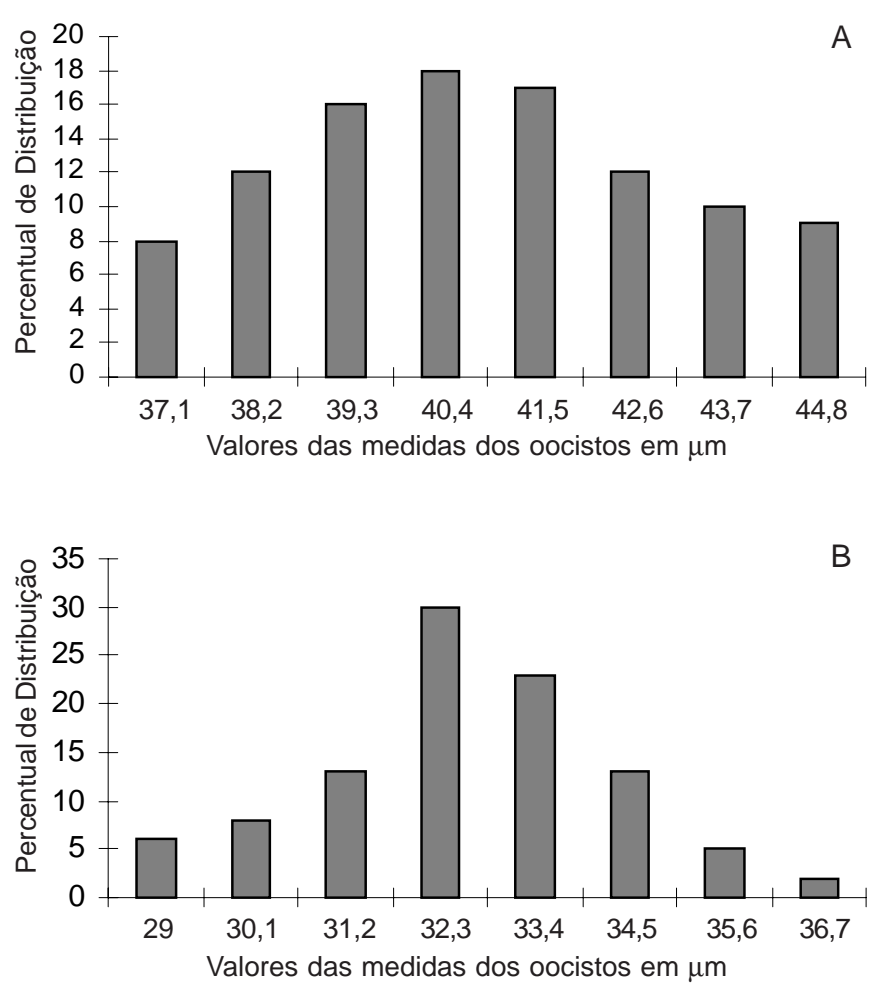

Figura 3: Intervalo de classe de oocistos esporulados de Cystoisospora felis oriundos de infecção experimental de gatos com $10^{5}$ oocistos esporulados. Diâmetros, maior (A) e menor (B).
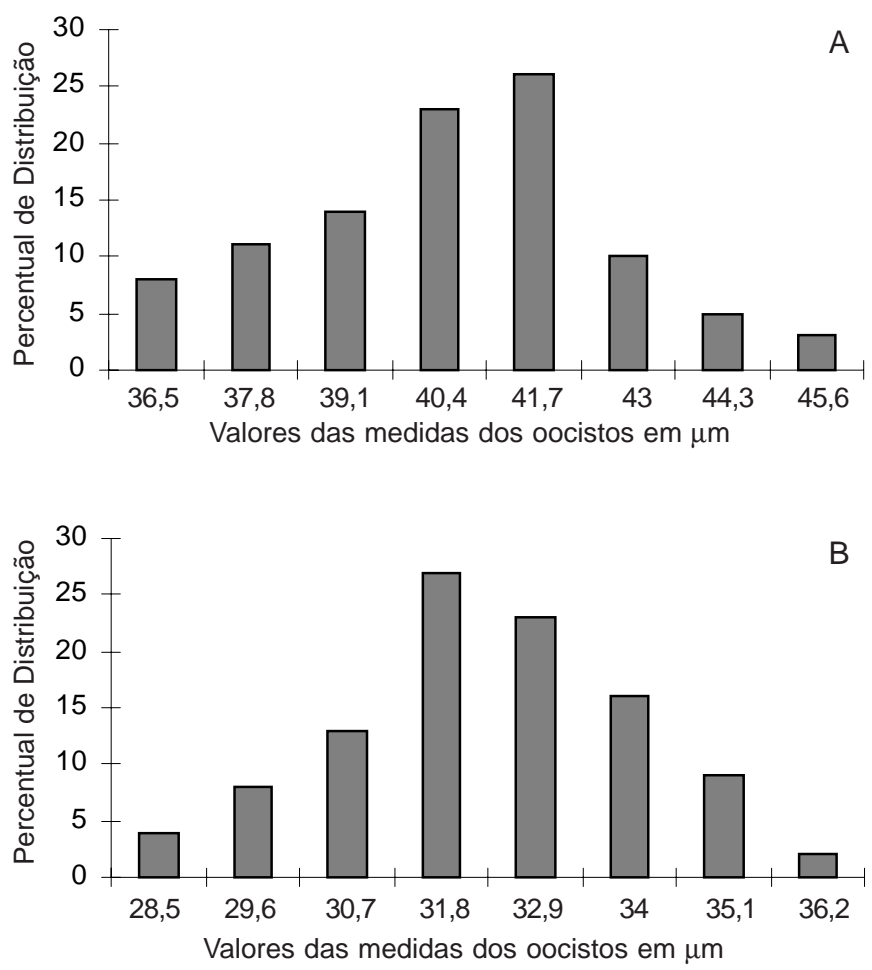

Figura 4: Intervalo de classe de oocistos esporulados de Cystoisospora felis oriundos de infecção experimental de gatos com hipnozoítas de vísceras de camundongos infectados com $10^{5}$ oocistos esporulados. Diâmetros, maior $(A)$ e menor (B). 
Desta maneira, vísceras contendo hipnozoítas de C. felis induziram a eliminação de oocistos maiores que os provenientes de infecções experimentais com oocistos esporulados ou oriundos de infecções naturais. Estes resultados corroboram com os de Carvalho Filho et al. (2003), onde foi observado que oocistos provenientes de infecção por hipnozoítas induz eliminação de oocistos maiores do que os eliminados de infecção

\section{Referências}

BOMFIM, T.C.B. DO; LOPES, C.W.G. Características morfométricas dos oocistos de Cryptosoridium muris Tyzzer, 1907 (Apicomplexa: Cryptosoridiidae) em Rattus norvergicus procedentes de dois habitats. Rev. Bras. Parasitol. Vet., v. 7, p. 125-132, 1998.

CARVALHO FILHO, P.R. de; MELO, P.S.; MASSAD, F.V. et al. Determinação da infecção de suínos por Cystoisospora felis (Wenyon, 1923) Frenkel, 1977 (Apicomplexa: Cystoisosporinae) através de prova biológica em felinos livres de coccídios. Rev. Bras. Parasitol. Vet., v.12, p. 37-42, 2003.

COSTA P.S. da; LOPES, C.W.G. Avaliação do parasitismo por Cystoisospora felis (Wenyon, 1923) Frenkel, 1977 (Apicomplexa: Cystoisosporinae) em coelhos tipo carne. Rev. Bras. Parasitol. Vet., v. 7, p. 15-19, 1998.

DUBEY, J.P. Life cycle of Isospora rivolta (Grassi, 1879) in cats and mice. J. Protozool., v. 26, p. 433-443, 1979.

DUBEY, J.P.; FRENKEL, J.K. Extra-intestinal stages of Isospora felis and I. rivolta (Protozoa:Eimeriidae) in cats. J. Protozool., v. 19, p. 8992, 1972.

FAYER, R. Epidemiology of protozoan infections: the Coccidia. Vet. Parasitol., v. 6, p. 75-103, 1980.

FAYER, R.; FRENKEL, J.K. Comparative infecddtivity for calves of oocysts of feline coccidia: Besnoitia, Hammondia, Cystoisospora, Sarcocystis and Toxoplasma. J. Parasitol., v. 65, p. 756-762, 1979.

FREIRE, R. B.; LOPES, C. W. G. Distribuição de hipnozoítas de Cystoisospora felis (Wenyon, 1923) Frenkel, 1977 (Apicomplexa: Sarcocystidae) em camundongos albinos experimentalmente infectados. Rev. Bras. Parasitol. Vet., v. 5, p. 23-28, 1996.

FRENKEL, J.K.; DUBEY, J.P. Rodents as vectors for feline coccidia, Isospora felis and Isospora rivolta. J. Infec. Dis., v. 125, p. 69-72, 1972.

GARDNER, S.L.; DUSZYNSKI, D.W. Polymorphism of eimerian oocysts can be a problem in naturally infected hosts: an exemple from subterranean rodents in Bolivia. J. Parasitol., v. 76, p. 805-811, 1990. HERZOG, J.D.; COSTA, P.S. da; FREIRE, R.B. et al. Hipnozoítas de Cystoisospora felis em cobaios. In: SEMINÁRIO BRASILEIRO DE PARASITOLOGIA VETERINÁRIA. 8, 1993. Londrina. Anais... Londrina: CBPV. p. 9, 1993. experimental com oocistos esporulados. Outro fato observado é que infecções naturais induzem a eliminação de oocistos menores que os provenientes de infecção por oocistos esporulados. O estresse pelo cativeiro, infecção por oocistos com longa exposição a fatores ambientais ou por hipnozoítas com tempo de encistamento muito prolongado poderiam induzir eliminação de oocistos morfometricamente menores.

HITCHCOCK, D.J. The life cycle of Isospora felis in the kitten. J. Parasitol., v. 41, p. 383-393, 1990.

LICKFELD, K.G. Untersuchunger über das katzencoccid Isospora felis (Wenyon, 1923). Arch. Protistenkd, v. 103, p. 427-456, 1959.

LINDSAY, D.S.; BLAGBURN, B.L. Biology of mammalian Isospora. Parasitol. Today, v. 10, p. 214-220, 1994.

LOSS, Z.G.; LOPES, C.W.G. Tratamento durante a gestação e no período pós-parto com sulfadiazina associada à pirimetamina de gatas portadoras de infecção natural por Cystoisospora felis (Wenyon, 1923) e C. rivolta (Grassi, 1879) (Apicomplexa: Cystoisosporinae). Rev. Bras. Parasitol. Vet., v. 6, p. 57-60, 1997.

MELO, P.S.; CARVALHO FILHO, P.R. DE; LOPES, C.W.G. er al. Hypnozoites of Cystoisospora felis (Wenyon, 1923) Frenkel, 1977 (Apicomplexa: Cystoisosporinae) isolated form piglets experimentally infected. Rev. Bras. Parasitol. Vet., v. 12 n. 2, p. 82-84, 2003.

MENEZES, R. de C.A.A. de; LOPES, C.W.G. Epizootiologia da Eimeria arloingi em caprinos na microrregião serrana fluminense, Rio de Janeiro. Rev. Univ. Rural: Ciênc. Vida, v, 17, p. 5-12, 1995.

NORTON, C.C.; JOYNER, L.P. Eimeria acervulina and E. mivati: oocysts, life-cycle and ability to develop in the chicken embryo. Parasitology, v. 83, p. 269-279, 1981.

OLIVEIRA F.C.; STABENOW, C. DAS.; MASSAD, F.V. et al. Hypnozoites of Cystoisospora Frankel, 1977 (Apicomplexa: Cystoisosporinae) in Mongolian gerbil lymph nodes and their transmission to cats free of coccidia. Rev. Bras. Parasitol. Vet., v. 16, n. 2, p. 72-76, 2007.

PEREIRA, M.J.S.; FONSECA, A.H.; LOPES, C.W.G. Regressão linear na caracterização de variações morfométricas em Coccidia. Rev. Bras. Parasitol. Vet., v. 10, n. 2, p. 75-78, 2001.

SAMPAIO, I.B.M. Estatística aplicada à experimentação animal. 2. ed. Belo Horizonte: Fundação de Ensino e Pesquisa em Medicina Veterinária e Zootecnia. 2002. 264 p.

SHA, H.L. The life cycle of Isospora felis Wenyon, 1923, a coccidium of the cat. J. Protozool., v. 18, n. 1, p. 3-17, 1971.

TENTER, A.M.; BARTA, J.R.; BEVERIDGE, I. et al. The conceptual basis for a new classification of the coccidia. Int. J. Parasitol., v. 32, p. 595616, 2002.

WENYON, C.M. Coccidiosis of cats and dogs and the status of the Isospora of man. Ann. Trop. Med. Parasitol., v. 17, p. 231-288, 1923. 